\title{
Structure and biosynthesis of histocompatibility antigens (H-2, HLA)
}

\author{
By B. Dobberstein, S. Kvist and Lynne Roberts $\dagger$ \\ European Molecular Biology Laboratory, Postfach 10.2209, D-6900 Heidelberg, F.R.G.
}

\begin{abstract}
Histocompatibility antigens (H-2K, D and L, and HLA-A, B and C) are highly polymorphic cell surface proteins. Their primary structure has been determined by sequencing the protein, complementary DNAs (cDNAs) or genes in several laboratories. $\mathrm{H}-2 \mathrm{~L}^{\mathrm{d}}$ and $\mathrm{K}^{\mathrm{d}}$ antigens are encoded by eight separate exons: one encodes the signal sequence, three encode the external domains, one encodes the membrane spanning segment and three encode the cytoplasmic domain. A similar structural organization has been found for an HLA gene.

H-2 and HLA antigens are synthesized on membrane-bound ribosomes and are co-translationally inserted into the membrane of the endoplasmic reticulum. Here they assemble with $\beta_{2}$-microglobulin, a small secretory protein. We describe the structure, the membrane insertion in vitro and in vivo, the intracellular transport and the surface expression of these antigens.
\end{abstract}

\section{INTRODUGTION}

Glycoproteins of the plasma membrane play important roles in several aspects of cellular recognition (see Warren 1980). Among these proteins are the major histocompatibility antigens called H-2K, D and L in mouse and HLA-A, B and C in man (Klein r979; Ploegh et al. 198r). As they were originally detected as the targets for aggressive $\mathrm{T}$ cells in the graft rejection they are also called the major transplantation antigens. Their physiological role might, however, be their function as a restricting element in T-cell killing of infected self cells (Zinkernagel \& Doherty 1974).

In recent years progress has been made in gaining an understanding of how plasma membrane proteins are synthesized, are inserted into the membrane, become modified and finally appear on the cell surface. Much has been learned by studying the biogenesis of viral membrane proteins (Katz et al. 1977; Garoff et al. 1978, 1982; Tabas \& Kornfeld 1978). Because they are made in large quantities in the infected cell they are easily approachable for biochemical analysis. The H-2 and HLA antigens became a useful system with the availability of antibodies of high specificity and titre. In this way, the obstacle posed by the low cellular content of $\mathrm{H}-2$ and HLA antigens could be overcome, allowing studies on the biosynthesis and cellsurface expression of these antigens. They are particularly interesting as they are composed of two subunits: one membrane-integrated and one soluble. The primary structure of an $\mathrm{H}-2$ and HLA antigen has been determined recently and genes coding for them have been characterized (Orr et al. 1979; Trägårdh et al. 1980; Nathenson et al. 1981; Moore et al. 1982; Evans et al. 1982; Kvist et al. 1982; Malissen et al. 1982). Here we describe the structure and the stages in the maturation of $\mathrm{H}-2$ and HLA antigens, established by work in several laboratories.

$\dagger$ Present address: Department of Biological Sciences, University of Warwick, Goventry CV4 7AL, U.K. 


\section{STRUCTURAL FEATURES}

(a) The extracellular portion

On the cell surface H-2 and HLA antigens are composed of a polymorphic heavy chain $(43-48 \mathrm{kDa})$ and a non-covalently linked small polypeptide, $\beta_{2}$-microglobulin $(11.5 \mathrm{kDa})$ (Cresswell et al. 1974; Peterson et al. 1974). The heavy chain is glycosylated and spans the membrane (Parham et al. 1977; Nathenson \& Cullen 1974; Walsh \& Crumpton 1977). The amino terminus of the molecule is exposed extracellularly and this portion can be cleaved close to the membrane by papain (see figure 1) (Coligan et al. 1981; Henning et al. 1976).

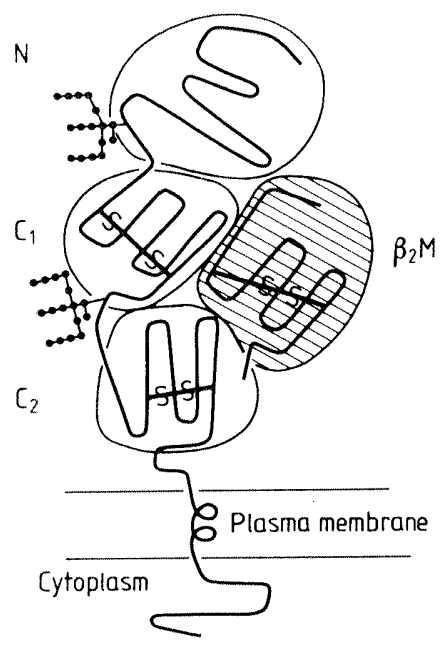

Figure 1. Schematic representation of a histocompatibility antigen class 1 H-2 molecule, modified after Coligan et al. (1981). The domains shown are indicated as follows: $\mathrm{N}, \mathrm{N}$-terminal domain; $\mathrm{C}_{1}$ and $\mathrm{C}_{2}$, cystine-containing domains; $\beta_{2} \mathrm{M}, \beta_{2}$-microglobulin polypeptide.

The primary structure of $\mathrm{H}-2$ and HLA antigens has been determined either by sequence analysis of the protein itself or by sequencing cDNAs or genes coding for them (Coligan et al. 1981; Lalanne et al. 1982; Moore et al. 1982; Ploegh et al. 1981 a; Kvist et al. 1982; Steinmetz et al. $198 \mathrm{I}$; Malissen et al. $\mathrm{r}_{982}$ ). The $\mathrm{H}-2 \mathrm{~K}^{\mathrm{b}}$ antigen (an $\mathrm{H}-2$ antigen coded by a gene of the $\mathrm{K}$ locus of the $\mathrm{b}$ allele) is 346 amino acids long; the HLA-B7 antigen (an HLA antigen coded by a gene in the B locus of the allele 7 ) is 337 amino acids long (Coligan et al. 1981; Ploegh et al. 198 1 a). A cluster of hydrophobic or uncharged amino acids is located close to the carboxyterminus between amino acids 283 and 307 (Nathenson et al. 1981). This segment most probably spans the membrane. The cysteine residues forming intrachain disulphide linkages are found at residues 101, 164, 203 and 259 in the $\mathrm{H}-2 \mathrm{~K}^{\mathrm{b}}$ molecule (Coligan et al. $\mathrm{r} 98 \mathrm{I}$ ). Based on susceptibility to cleavage by acid or proteolytic enzymes, as well as the location of the two intrachain disulphide linkages, the extracellular part can be divided into three domains. They have been designated $\mathrm{N}(\alpha 1)$ for the amino-terminal domain, $\mathrm{C} 1(\alpha 2)$ and $\mathrm{C} 2(\alpha 3)$ for the cysteine-containing domains (Terhorst et al. 1977; Nathenson et al. 1981). Such an organization is also supported by the location of the exon-intron boundaries in the genes coding for $\mathrm{H}-2$ and HLA antigens; three exons encode the extracellular portion and the size of each of them is in excellent agreement with the size of the domains suggested by the analysis of the protein itself 
(Moore et al. 1982; Malissen et al. 1982; Kvist et al. 1982). The N-terminal domain is comprised of residues 1-90, the C1 domain 91-182 and the C2 domain 183-274 (see figure 2) (Moore et al. 1982; Kvist et al. 1982; Malissen et al. 1982).

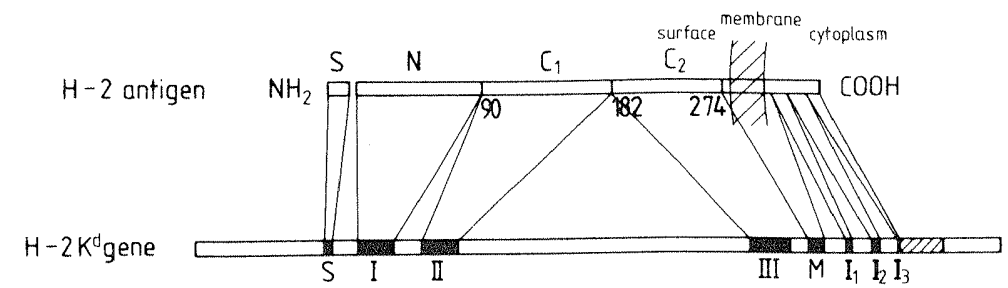

Figure 2. Organization of the $H-2 K^{\mathrm{d}}$ gene. Comparison of its exon-intron structure with the $\mathrm{H}-2 \mathrm{~K}^{\mathrm{b}}$ antigen and the cDNA for an $\mathrm{H}-2 \mathrm{~K}^{\mathrm{d}}$ antigen (Coligan et al. 1980 ; Kvist et al. 1982). Exons corresponding to protein domains are shown as filled boxes, introns as open boxes, and the $3^{\prime}$ untranslated region as a hatched box. The exons are indicated by: $\mathrm{S}$, coding for the signal sequence; I, II, III, coding for the external protein domains $\mathrm{N}, \mathrm{C}_{1}$ and $\mathrm{C}_{2} ; M$, coding for the membrane domains; and $\mathrm{I}_{1}, \mathrm{I}_{2}, \mathrm{I}_{3}$, coding for the intracellular segment.

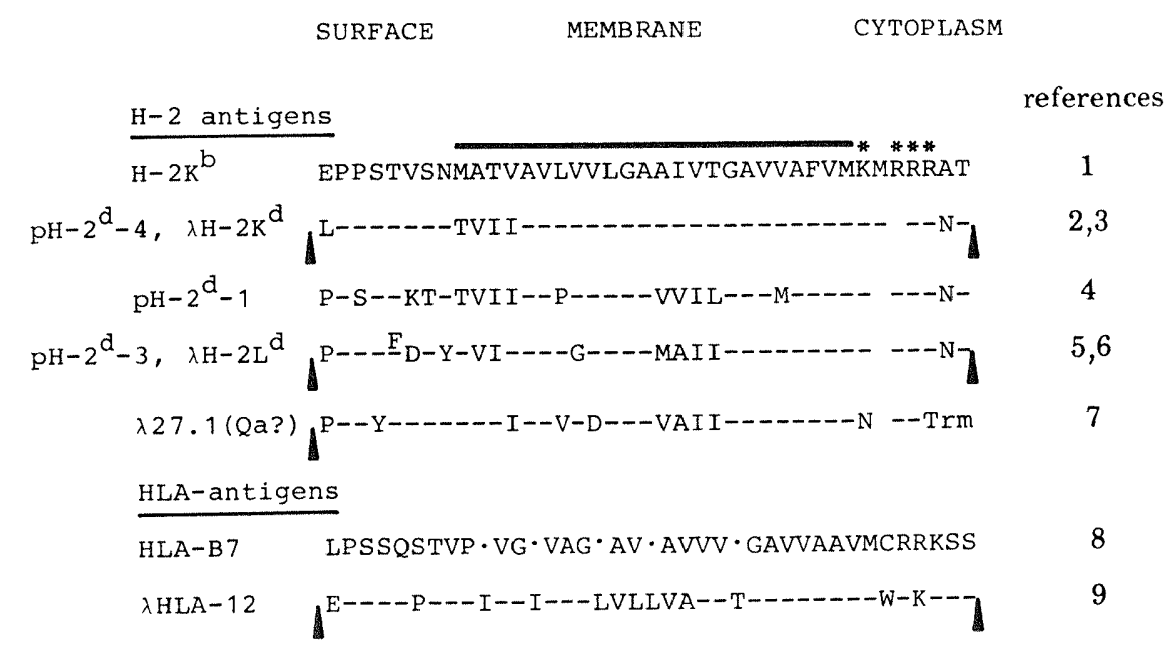

FIGURE 3. Comparison of the amino acid sequence of the membrane-spanning segment. The sequence is expressed in the one-letter code. Dashes indicate homology to the H-2K $\mathrm{K}^{\mathrm{b}}$ and HLA-B7 sequence respectively. Dots indicate that the amino acid at that site is not known. The sequence has been obtained by sequencing the protein (H-2K $\left.\mathrm{K}^{\mathrm{b}}, \mathrm{HLA}-\mathrm{B} 7\right)$, cDNA $\left(\mathrm{pH}_{-} 2^{\mathrm{d}-4}, \mathrm{pH}-2^{\mathrm{d}}-1, \mathrm{pH}-2_{-}^{\mathrm{d}}-3\right)$ or the gene $\left(\lambda 27.1, \lambda \mathrm{HLA}-12, \lambda \mathrm{H}_{-2} \mathrm{~L}^{\mathrm{d}}\right.$, $\left.\lambda \mathrm{H}-2 \mathrm{~K}^{\mathrm{d}}\right)$. The arrow indicates a splice site in the gene. Basic amino acid residues at the cytoplasmic side are indicated by an asterisk. References: 1, Coligan et al. (1981); 2, Lalanne et al. (1982);3, Kvist et al. (1982); 4, Kvist et al. (198I); 5, Bregegere et al. (198I); 6, Moore et al. (1982); 7, Steinmetz et al. (1981); 8, Ploegh et al. (198r); 9, Malissen et al. (1982).

The number of carbohydrate units on H-2 and HLA antigens can vary greatly. Only one unit is found in HLA antigens, whereas up to three are present in $\mathrm{H}-2$ antigens. They are linked to an asparagine at position 86 , in $\mathrm{H}-2$ antigens also on asparagine 176 , and in the $\mathrm{H}-2 \mathrm{~K}^{\mathrm{d}}$ molecule on residue 256 as well (Parham et al. 1977; Nathenson et al. 1981; Kvist et al. 1982).

\section{(b) The membrane-spanning segment}

By using proteases as a dissecting tool, the location of the membrane-spanning segment of H-2 and HLA antigens has been determined (see below) (Dobberstein et al. 1979; Owen et al. I980). It is made up of about 30 amino acids and it located about 30 residues away from the carboxy terminus. One would predict that such a segment contains a stretch of uncharged or 
hydrophobic residues, or both, that are able to interact with the hydrophobic lipid bilayer. A segment with this property is contained in the amino acid sequence of $\mathrm{H}-2$ and HLA antigens. Figure 3 shows a comparison of the amino acid sequences of the membrane-spanning segments. Although the amino acids may differ, the hydrophobic character of this segment was conserved in all chains sequenced so far. Changes were detected mainly in the region close to the external side of the membrane. The cluster of basic amino acid residues on the cytoplasmic side is conserved, suggesting a general function of this region in anchoring the protein in the membrane.

A separate exon codes for the membrane spanning segment plus some amino acid residues on either side (see figures 2 and 3) (Moore et al. 1982; Malissen et al. 1982; Kvist et al. 1982). This arrangement leads one to ask if a functional membrane segment is composed of three portions: (1) amino acid residues forming a link between the membrane and external domains, (2) the lipid bilayer-spanning segment, and (3) the cluster of basic amino acid residues on the cytoplasmic side of the membrane.

\section{(c) The cytoplasmic segment}

Little is known about the function of the cytoplasmic segment of plasma membrane proteins. It has been suggested that their function is to transmit 'signals' from the outside to the inside of the cell by interacting with cytoplasmic constituents (Bourguignon \& Singer 1977; Koch \& Smith 1978; Pober et al. 1981). No such functional interaction with cytoplasmic elements has yet been demonstrated. The size of the cytoplasmic segment can be estimated on antigens that are inserted into microsomes. Microsomes are closed vesicles derived from the endoplasmic reticulum, where the insertion of newly synthesized plasma membrane proteins like $\mathrm{H}-2$ and HLA antigens occurs (see below). When these vesicles were treated with protease only the portion of the antigen that protruded from the membrane into the cytoplasm was digested. The remainder of the molecule was protected against digestion by the permeability barrier of the membrane. After separation of the intact and proteolysed antigens on sodium dodecyl sulphate (SDS)-polyacrylamide gels, the size of the cytoplasmic segment could be calculated from their difference in molecular mass. The size of the cytoplasmic segment of $\mathrm{H}-2$ and HLA antigens has been estimated to contain about 30 amino acid residues (Dobberstein et al. 1979; Owen et al. 1980). This estimated size is in good agreement with the 30-40 amino acid residues determined by sequence analysis of H-2 and HLA proteins, cDNAs and genes. Figure 4 shows sequences of cytoplasmic segments. Here the sequences are most varied, in particular with regard to their size. The strong variation may either indicate the existence of little functional constraint on this segment or reflect different modes of interaction with cytoplasmic components.

The cytoplasmic segment is encoded in $\mathrm{H}-2$ genes by three exons and in an HLA gene by two (Moore et al. 1982; Kvist et al. 1982; Malissen et al. 1982). As the exons encoding signal sequences, cytoplasmic and membrane domains all correlate very well with functionally or structurally defined regions, it is tempting to speculate that separate functions might also be indicated by the different exons coding for the cytoplasmic segments. Such a hypothesis can be tested. H-2 genes, isolated by molecular cloning, can be expressed after stable transformation in mouse $\mathrm{L}$ cells (Goodenow et al. 1982; Burgert et al. 1982; Evans et al. 1982). H-2 antigens became expressed and can function on the cell surface as restricting elements in T-cell killing (Örn $e$ t al. 1982). This system should also allow one to test modified genes, e.g. those modified in their cytoplasmic segment. H-2 genes could be expressed that are modified with regard to the number and composition of the exons coding for the cytoplasmic segment. It would for instance be 
important to establish whether a particular G-terminal segment is required for the T-cell killing of an infected cell.

\section{(d) $\beta_{2}$-Microglobulin}

The small subunit of $\mathrm{H}-2$ and HLA antigens has been identified as $\beta_{2}$-microglobulin (Cresswell et al. 1974; Peterson et al. 1974; Rask et al. 1974). It has a molecular mass of about $12 \mathrm{kDa}$ and contains 99 and 100 amino acid residues in mouse and man respectively (Cunningham et al. 1973; Gates et al. 1981). Based on the homology between immunoglobulin constant regions and

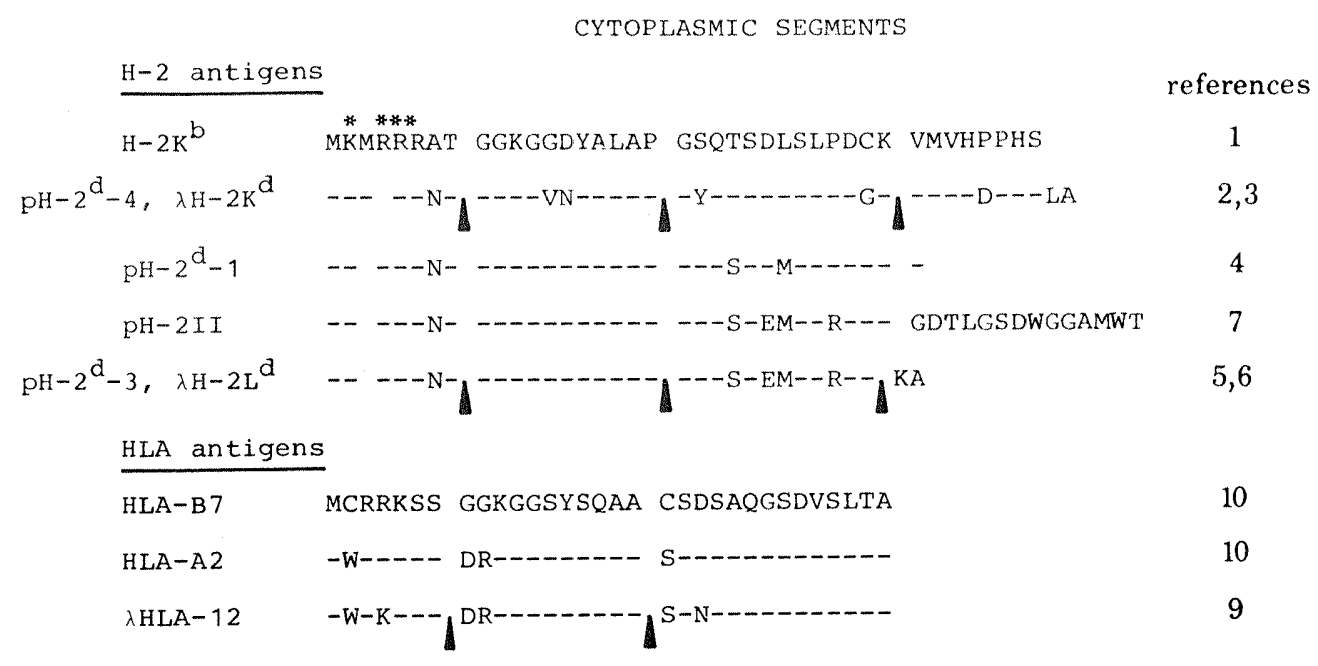

FIGURE 4. Comparison of cytoplasmic segments. Sequences have been determined by sequencing the protein $\left(\mathrm{H}-2 \mathrm{~K}^{\mathrm{b}}, \mathrm{HLA}-\mathrm{B} 7, \mathrm{HLA}-\mathrm{A} 2\right)$, cDNA (pH-2 $\mathrm{d}, \mathrm{pH}-2^{\mathrm{d}}-1, \mathrm{pH}$ 2II, $\left.\mathrm{pH}-2^{\mathrm{d}}-3\right)$ or the gene $\left(\lambda \mathrm{H}-2 \mathrm{~L}^{\mathrm{d}}, \lambda \mathrm{H}-2 \mathrm{~K}^{\mathrm{d}}\right.$, $\lambda$ HLA-12). Dashes indicate sequence homology with the H-2K $\mathrm{K}^{\mathrm{b}}$ and HLA-B7 antigen respectively. Arrow indicate a splice site in the gene. The cluster of basic amino acids is indicated by asterisks. References as in figure 3, plus: 10, Robb et al. (1978).

the $\mathrm{C} 2$ domain of $\mathrm{H}-2$ antigens, it has been suggested that it interacts with the $\mathrm{C} 2$ domain (Ploegh et al. 1981 $a$ ). This is supported by the finding that the exons encoding the C2 domain are highly conserved between different $\mathrm{H}-2$ genes (Steinmetz et al. 1982). This conservation could reflect the evolutionary constraint on this domain posed by the interaction with $\beta_{2^{-}}$ microglobulin. The function of $\beta_{2}$-microglobulin in the oligomeric complex with the heavy chains is unknown.

\section{BIOSYNTHESIS}

Early studies on the biosynthesis of H-2 and HLA antigens indicated that they were synthesized at an intracellular site and were subsequently transported to the plasma membrane (Vitetta \& Uhr 1975). It was suggested that they are synthesized and transported like secretory proteins, going from the rough endoplasmic reticulum via the Golgi complex to the plasma membrane. Pulse-chase techniques and cell fractionation were then used to follow the flow of newly synthesized membrane constituents to the cell surface (Krangel et al. 1979; Dobberstein et al. 1979; Owen et al. 1980; Croze \& Morré 1981; Tartakoff et al. 1981 ). Labelled H-2 antigens appeared first in fractions containing membranes derived from the endoplasmic reticulum, then from the Golgi apparatus and last from the plasma membrane. 


\section{(a) Membrane insertion}

The heavy chain and $\beta_{2}$-microglobulin both have to cross a membrane - at least in part for the heavy chain - to go from their site of synthesis to their final location, the plasma membrane. Steps in the biosynthesis of plasma membrane proteins can be investigated in cell-free protein synthesizing systems as well as in vivo by metabolic labelling. Both of these approaches have been used for studying H-2 and HLA antigens.

Heavy chains and $\beta_{2}$-microglobulin are translated from separate mRNAs. These can be separated on a sucrose gradient and show sedimentation values of $17 S$ and $9 S$, respectively (Dobberstein et al. 1979; Jay et al. 1979).

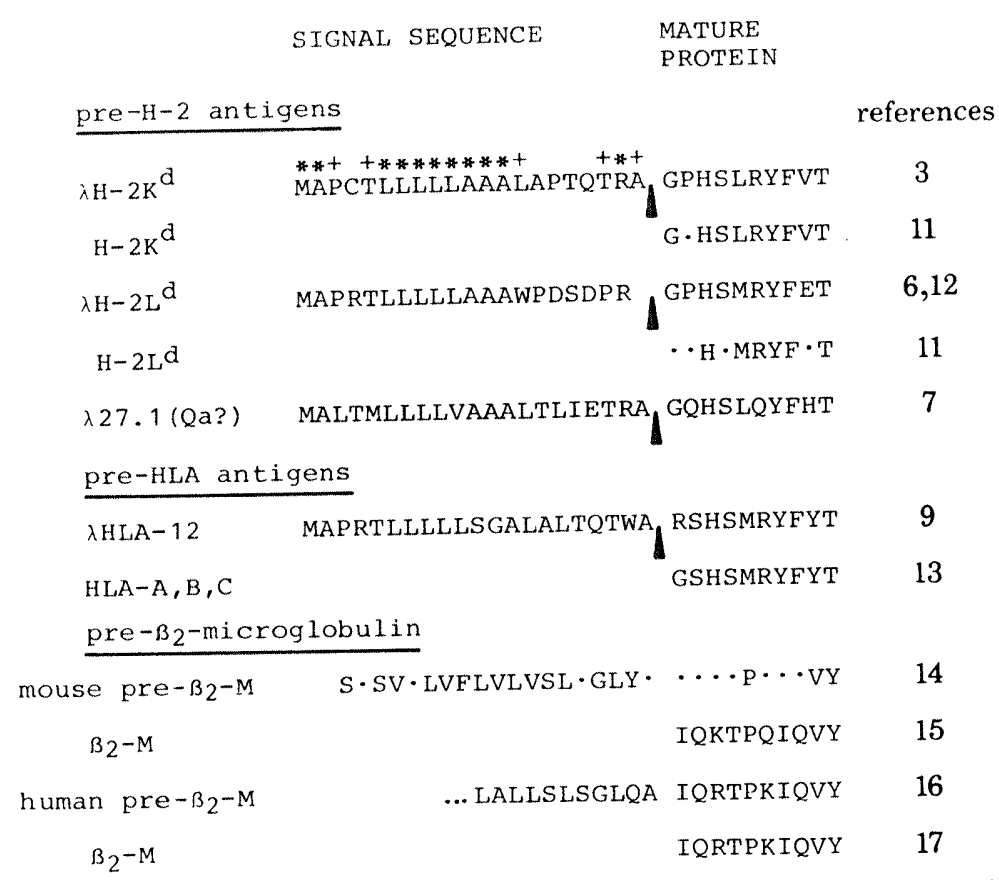

Figure 5. Comparison of signal sequences. Sequences were determined by sequencing proteins $\left(\mathrm{H}-2 \mathrm{~K}^{\mathrm{b}}, \mathrm{H}^{-}-2 \mathbf{L}^{\mathrm{d}}, \boldsymbol{\beta}_{2^{-}}\right.$ microglobulin), cDNA (pre- $\beta_{2}$-microglobulin) or genes $\left(\lambda \mathrm{H}-2 \mathrm{~K}^{\mathrm{d}}, \lambda \mathrm{H}-2 \mathrm{~L}^{\mathrm{d}}, \lambda 27.1\right)$. Dots indicate an unknown amino acid at that position. Arrows point at the site of postulated signal peptidase cleavage and splice site in the gene. An asterisk indicates an amino acid residue conserved in signal sequences of all three pre- $\mathrm{H}-2$ antigens, a cross indicates an amino acid conserved in two. References as in figure 3, plus: 11, Coligan et al. (1980); 12, Evans et al. (1982); 13, Trägårdh et al. (1980); 14, Lingappa et al. (1979); 15, Gates et al. (1981); 16, Suggs et al. (1981); 17, Cunningham et al. (1973).

When mRNA from cells expressing large amounts of H-2 and HLA antigens were translated in a cell-free system, both were synthesized as higher molecular mass precursors (Dobberstein et al. 1979; Ploegh et al. 1979). The heavy chain (pre-H-2Dd ) was found to be $2 \mathrm{kDa}$ heavier than its non-glycosylated, membrane-inserted counterpart (see below). Precursors to a large number of secretory and some membrane proteins have been characterized (Kreil 198r). At their amino termini they contain a signal sequence that is cleaved from the nascent chain during its insertion into the membrane of the endoplasmic reticulum. It is thought to direct the nascent polypeptide chain to the endoplasmic reticulum and facilitate its insertion into the membrane (see Blobel 1980). Figure 5 shows the signal sequences of some $\mathrm{H}-2$ and HLA antigens (Moore 
et al. 1982; Kvist et al. 1982; Malissen et al. 1982). They were deduced from the nucleotide sequences of their genes. The signal sequences in these genes are encoded by separate exons (see figure 5). They comprise 20 or 21 amino acid residues and contain a central region devoid of charged residues, the characteristic feature of a signal sequence. The $\mathrm{NH}_{2}$-terminal half of the signal sequence of $\mathrm{H}-2$ antigens shows a strikingly higher degree of conservation than the region close to the site of signal peptidase cleavage (see figure 5). This could indicate that higher constraint is exerted on the amino-terminal half. The stretch of hydrophobic amino acids is located in this portion, which would strongly support the notion that such a hydrophobic region is essential for signal sequence function. Amino acids with short side chains, such as Gly, Ala, Cys and Ser, are usually present at the site of signal sequence cleavage (Kreil r98r). In the $\mathrm{H}-2 \mathrm{~L}^{\mathrm{d}}$ antigen an asparagine residue has been found at this site. A sequencing error is unlikely as two groups obtained the same result independently (Moore et al. 1982; Evans et al. 1982). Because the sequence was deduced from a genomic clone it would be important to confirm the splice site by sequencing part of the cDNA or the preprotein itself.

As already mentioned, the insertion of proteins into a membrane can be reproduced in vitro by using rough microsomes derived from dog pancreas (Blobel \& Dobberstein 1975). In such a system $\mathrm{H}-2$ antigens were inserted co-translationally into the membrane (Dobberstein et al. r979). The concomitant biosynthesis of $\beta_{2}$-microglobulin was not required for the insertion of the heavy chains into the membrane. The disposition of the heavy chain in the membrane of the endoplasmic reticulum was the same as that on the cell surface, i.e. the carboxy terminus was on the cytoplasmic side and the amino terminus on the luminal side.

Heavy chains inserted into microsomal membranes in vitro became glycosylated. This was evidenced by a shift to a higher molecular mass when these antigens were separated on an SDS-polyacrylamide gel, and by their binding to lentil lectin (Dobberstein et al. 1979).

Heavy chains labelled for $5 \mathrm{~min}$ in vivo were also glycosylated because they also bound to lentil lectin. Their carbohydrate unit was sensitive to endoglycosidase $\mathrm{H}$ (Owen et al. 1980; Sege et al. 1981; Krangel et al. 1979). This enzyme is known to cleave polymannose-type carbohydrates linked to asparagine (Tarentino \& Maley 1974).

The glycosylation of the heavy chains was blocked in vivo by tunicamycin, an inhibitor of $N$ linked glycosylation (Ploegh et al. 198r $b$ ). Glycosylation was required neither for the insertion of heavy chains into the membrane nor for their assembly with $\beta_{2}$-microglobulin. Unglycosylated heavy chains became correctly integrated into the membrane of the endoplasmic reticulum, as evidenced by protection against protease (see above). Antibodies recognizing exclusively the non-glycosylated heavy chain did co-precipitate $\beta_{2}$-microglobulin.

Biosynthesis of $\beta_{2}$-microglobulin proceeds very similarly to that of other secretory proteins (Dobberstein et al. 1979; Lingappa et al. 1979; Algranati et al. 1980). This molecule can in fact be considered as a secretory protein that becomes a peripheral membrane protein only upon association with the membrane integrated heavy chain. In a cell-free system devoid of membranes it was synthesized as a higher molecular mass precursor (pre- $\beta_{2}$-microglobulin) containing an amino-terminal signal sequence (Dobberstein et al. 1979; Algranati et al. 1980). Figure 5 shows the partial sequences of the signal sequences of $\beta_{2}$-microglobulin from mouse and man (Lingappa et al. 1979; Suggs et al. 1981). In mouse it comprises 19 amino acids. When $\beta_{2}$-microglobulin was synthesized in vitro in the presence of dog pancreas microsomal membranes, it was cotranslationally translocated across this membrane and the signal sequence was cleaved. When protease was used to probe the topology of $\beta_{2}$-microglobulin in microsomal vesicles, it was found 
to be fully protected by the membrane (Dobberstein et al. 1979). Thus, in contrast to the heavy chain, $\beta_{2}$-microglobulin is completely translocated across the membrane. This was to be expected because $\beta_{2}$-microglobulin does not contain a stretch of hydrophobic or uncharged amino acid residues that could anchor it in the membrane.

A number of secretory and membrane proteins compete for specific sites on microsomal membranes that are required for their membrane insertion. Proteins required for membrane translocation have been characterized recently. They comprise a 'signal recognition protein' complex and a membrane-integrated receptor, the 'docking protein' (Walter \& Blobel 1981; Meyer et al. 1982). Both of these proteins function sequentially in the recognition of the signal sequence on the nascent secretory or membrane protein and the subsequent specific interaction with the membrane. That the same mechanism also functions in the translocation of nascent $\beta_{2}$-microglobulin across the membrane is suggested by its competition with ovalbumin for sites in the membranes (Lingappa et al. 1979).

\section{(b) Oligomeric assembly}

Heavy chains and $\beta_{2}$-microglobulin are independently inserted into or translocated across the membrane of the endoplasmic reticulum. By using antibodies that detect heavy chains only, oligomeric assembly with $\beta_{2}$-microglobulin has been studied (Krangel et al. 1979; Owen et al. 1980; Dobberstein et al. 1979). In such a case $\beta_{2}$-microglobulin recovered in immunoprecipitates must have assembled with the heavy chains. In all cell lines studied, oligomeric assembly occurred very rapidly after newly synthesized heavy chains were inserted into the membrane of the endoplasmic reticulum. After as little as 5 min of pulse labelling of either the human lymphoblastoid cell lines Bri8 or T5-1 or the mouse cell line SL, $2, \beta_{2}$-microglobulin was found to be bound to the heavy chains (Krangel et al. 1979; Dobberstein et al. 1979; Owen et al. 1980). Whether nascent heavy chains do already assemble with $\beta_{2}$-microglobulin is unclear. The observed kinetics of association found in the cell line T5-1 suggests that $\boldsymbol{\beta}_{2}$-microglobulin can assemble with completed heavy chains. $\beta_{2}$-Microglobulin is synthesized in excess over the heavy chains, at least twofold in Bri8 cells (Owen et al. 1980). Excess $\beta_{2}$-microglobulin does not appear to be associated with other polypeptide chains. Results from pulse-chase experiments in Bri8 and SL2 cells are consistent with synthesis of an excess of $\beta_{2}$-microglobulin. The amount of labelled $\beta_{2}$-microglobulin increased steadily during the chase period, whereas the intensity of labelled heavy chains remained relatively constant. $\beta_{2}$-Microglobulin that was not associated with heavy chains remained largely in the endoplasmic reticulum (e.r.), whereas that assembled with the heavy chain underwent intracellular transport (Dobberstein et al. 1979). The fate of excess $\beta_{2^{-}}$ microglobulin in the e.r. has not yet been determined. It may be eventually secreted; however, this would proceed more slowly than the assembled antigens appear on the cell surface. Excess free $\beta_{2}$-microglobulin in the e.r. would provide the condition whereby newly synthesized heavy chains would assemble with an existing pool of $\beta_{2}$-microglobulin.

\section{INTRAGELLULAR TRANSPORT}

It is not known which determinants regulate the intracellular transport of plasma membrane proteins from the e.r. to the cell surface. From studies with viral membrane proteins it appears that these determinants can be different from one protein to another. Among the modifications 
that have been suggested to function in intracellular transport are glycosylation, phosphorylation, fatty acid acylation and oligomeric assembly. It is essential to determine how these modifications affect the surface expression of $\mathrm{H}-2$ or HLA antigens. A schematic illustration of the intracellular pathway of $\mathrm{H}-2$ and HLA antigens is shown in figure 6.

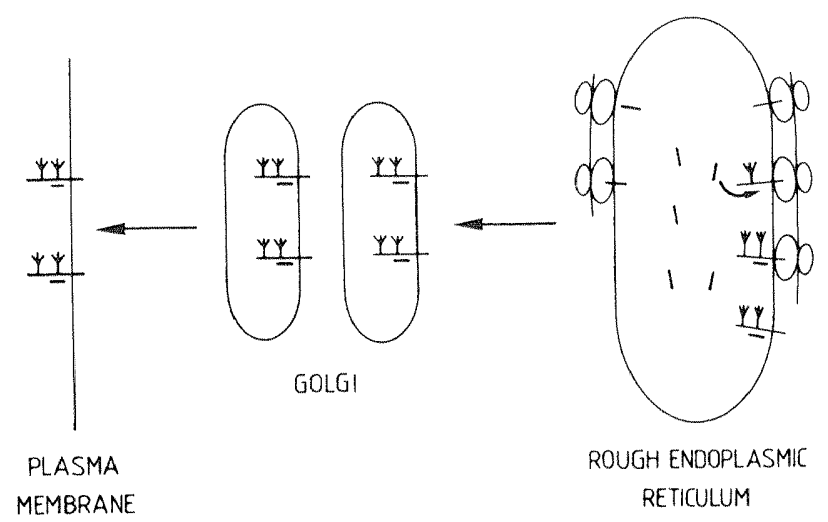

FIGURE 6. Schematic illustration of the intracellular pathway of H-2 and HLA antigens.

$\boldsymbol{\psi}$, Oligosaccharide;,$- \beta_{2}$-microglobulin, $\Psi \boldsymbol{\Psi}, \mathrm{H}-2$ and HLA heavy chain.

\section{(a) Carbohydrate modifications}

The carbohydrate portions of H-2 and HLA antigens are modified during intracellular transport in a manner similar to that of viral glycoproteins (Krangel et al. 1979; Owen et al. 1980; Ploegh et al. 198r; Sege et al. 198r). Asparagine-linked carbohydrate structures and their processing during intracellular transport are well characterized for a number of viral membrane proteins, in particular for the VSV-G protein (Tabas \& Kornfeld 1978). Polymannose-type oligosaccharide chains are transferred in the rough endoplasmic reticulum onto the nascent polypeptide chain (Rothman \& Lodish 1977; Kruppa 1979). After the removal of glucose and mannose residues, the mature complex-type oligosaccharide arises by the addition of $N$-acetyl glycosamine, galactose, fucose and sialic acid residues (Tabas et al. 1978; Tabas \& Kornfeld 1978). While the polymannose-type oligosaccharide is sensitive to endoglycosidase $\mathrm{H}$ (endo $\mathrm{H}$ ), the complex-type is not.

As judged by SDS-polyacrylamide gel electrophoresis, the apparent size of $\mathrm{H}-2 \mathrm{~K}^{\mathrm{d}}, \mathrm{D}^{\mathrm{d}}$ and HLA antigens increases 20-30 min after their synthesis (Dobberstein et al. 1979; Krangel et al. 1979; Sege et al. 1981). This usually indicates the conversion of the polymannose-type to complex-type carbohydrate. Likewise the endo $\mathrm{H}$ sensitive form of HLA antigens is modified to an insensitive one. Neuraminidase had no detectable effect on the endo $\mathrm{H}$ sensitive form; however, the endo $\mathrm{H}$ insensitive form was converted to a form of lower molecular mass (Sege et al. $198 \mathrm{I}$ ). This is consistent with the modification of a polymannose-type carbohydrate unit to a complex oligosaccharide unit containing sialic acid residues.

The carbohydrate portion is not necessary for the surface appearance of HLA antigens (Owen et al. 1980; Ploegh et al. 198I). Bri8 and JY cells treated with tunicamycin expressed HLA antigens on their surface. This was demonstrated by binding antibodies to intact cells before lysis and immunoprecipitation. Also, glycosylated and non-glycosylated heavy chains appeared on the cell surface at the same time, about 30 min after synthesis in both cell types studied. 
The Golgi complex is the intracellular location where conversion of polymannose-type to complex-type oligosaccharide is thought to occur. Passage of $\mathrm{H}-2^{\mathrm{d}}$ antigens through the Golgi complex has been investigated by Tartakoff et al. ( $198 \mathrm{I}$ ) using the ionophone monensin. This drug has been shown to interrupt the intracellular transport of secretory and viral membrane proteins at the level of the Golgi complex and to cause their accumulation within dilated Golgi cisternae. The proteins remain incompletely glycosylated, lacking fucose, galactose and sialic acid. Terminal glycosylation of $\mathrm{H}-2^{\mathrm{d}}$ antigens was blocked by monensin. Furthermore, indications were obtained that $\mathrm{H}_{-} 2^{\mathrm{d}}$ antigens in monensin-treated cells do not reach the cell surface. Thus H-2 antigens normally pass through the Golgi subsite defined by monensin and acquire terminal sialic acid distal to this site (Tartakoff et al. $198 \mathrm{r}$ ).

\section{(b) Assembly of HLA antigens with $\beta_{2}$-microglobulin}

From studies of HLA antigens in the human lymphoblastoid cell line Daudi it has been concluded that $\beta_{2}$-microglobulin is required for the cell-surface expression of the heavy chains (Ploegh et al. 1979; Owen et al. 1980; Sege et al. 1981; Goodfellow et al. 1975). This cell line does not synthesize $\beta_{2}$-microglobulin and does not express the heavy chains on its cell surface. Heavy chains are, however, synthesized by these cells. This was demonstrated convincingly by precipitating HLA heavy chains from pulse-labelled Daudi cells. Furthermore, the precursor of the heavy chains was isolated from the cell-free translation products of Daudi cell mRNA. No $\beta_{2}$ microglobulin could be detected in Daudi cells, neither after labelling in vivo nor after translation of their mRNA.

The heavy chains became glycosylated and this could be blocked by the inhibitor of $N$-linked glycosylation, tunicamycin. The carbohydrate portion of pulse-labelled heavy chains of Daudi cells remained endo $\mathrm{H}$ sensitive throughout a chase period of $90 \mathrm{~min}$ (Owen et al. 1980). Neuraminidase was unable to modify the chased heavy chains. No fucose was incorporated into heavy chains synthesized by Daudi cells in contrast to those of Bri8 cells (Sege et al. 198I). The stability of heavy chains, at least up to $90 \mathrm{~min}$, was not drastically reduced by the lack of association with $\beta_{2}$-microglobulin (Owen et al. 1980; Sege et al. 198I). Taken together these data demonstrate that the heavy chains of Daudi cells are arrested at an early stage of intracellular transport, most probably in the endoplasmic reticulum. They furthermore suggest that the association with $\beta_{2}$-microglobulin is necessary for intracellular transport of the heavy chains to the Golgi complex and the cell surface.

The requirement of $\beta_{2}$-microglobulin for the intracellular transport of HLA heavy chains is also suggested by studies on a structurally altered HLA-A2 heavy chain (Krangel et al. 1982). This chain became glycosylated and thus presumably inserted into the membrane of the endoplasmic reticulum in vivo. However, unlike the normal HLA-A2 heavy chains, the variant did not associate with $\beta_{2}$-microglobulin; neither did it undergo processing of its polymannose oligosaccharide nor could it be detected on the cell surface. The stability within the cell did not seem to be altered. Krangel et al. (1982) suggest that the primary defect in this HLA-A2 variant is the failure to associate stably with $\beta_{2}$-microglobulin.

It is not known why heavy chains alone cannot undergo intracellular transport. One possibility is that they aggregate with constitutive elements of the rough endoplasmic reticulum and thereby become unable to accumulate at sites where postulated transport vesicles bud from the endoplasmic reticulum membrane (Warren 1980; Pearse \& Bretscher 1981). 


\section{(c) Other modifications}

Besides glycosylation and assembly with $\beta_{2}$-microglobulin, $\mathrm{H}-2$ and HLA heavy chains become phosphorylated (Rothbard et al. 1980; Pober et al. 1978). This phosphorylation occurs on a serine residue in the cytoplasmic C-terminal end. The possibility, however, that the phosphorylation of the heavy chains occurs after lysis of the cells with detergent has not yet been ruled out. A second modification, a transglutaminase-catalysed amidation of the intracellular carboxy-terminal segment of HLA-B7 and A2 antigens, has been suggested (Pober \& Strominger I981). Transglutaminase couples amines specifically to glutamine residues. Pober \& Strominger (198I) suggest that cellular transglutaminases could be involved in membrane events by catalysing the cross-linking of the cytoplasmic portion of a transmembrane protein to other intracellular constituents. No such labelling in vivo has yet been demonstrated. As mentioned above, the use of modified heavy chains will be a means by which questions on the physiological function of these possible modifications could be answered in the future.

With the ability to isolate and express genes coding for plasma membrane proteins, their detailed characterization has become possible. The hydrophobic segments, which posed serious problems for the protein chemist, can be easily analysed by DNA sequencing technology. The expression of modified genes in different host cells will greatly facilitate an evaluation of the functionally relevant segments of the histocompatibility antigens.

The authors are very grateful to Wendy Moses and Annie Steiner for preparing the manuscript, Petra Riedinger for graphics and David Meyer for critical comments and reading of the manuscript.

\section{REFERENCES}

Algranati, J. D., Milstein, C. \& Ziegler, A. 1980 Eur. J. Biochem. 103, 197-207.

Blobel, G. 1980 Proc. natn. Acad. Sci. U.S.A. 77, 1496-1500.

Blobel, G. \& Dobberstein, B. 1975 J. Cell Biol. 67, 852-862,

Bourguignon, L. Y. W. \& Singer, S. J. 1977 Proc. natn. Acad. Sci. U.S.A. 74, 5031-5035.

Bourguign, F., Abastado, J. P., Kvist, S., Rask, L., Lalanne, J. L., Garoff, H., Cami, B., Wiman, K., Larhammar, 列

Burgert, H. G., Soderberg, K., Rüsch, E., Hämmerling, G.J., Kvist, S. \& Dobberstein, B. I982 EMBO Jl. (Submitted.)

Coligan, J. E., Kindt, T. J., Nairn, R., Nathenson, S. G., Sachs, D. H. \& Hansen, T.

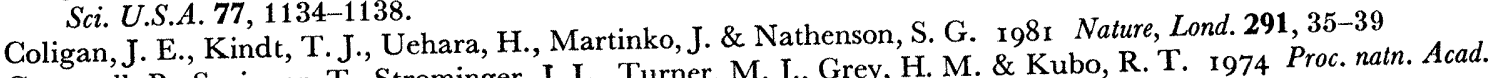

Cresswell, P., Springer, T., Stromir Sci. U.S.A. 71, 2123-2127.

Croze, E. M \& Morré, D. J. I98 I Proc. natn. Acad. Sci. U.S.A. 78, 1547-1551.

Cunningham, B. A., Wang, J. L., Berggard, J. \& Peterson, P. A. 1973 Biochemistry, Wash. 12, 4811-4821.

Dobberstein, B., Garoff, H., Warren, G. \& Robinson, P. r979 Cell 17, 759-769.

Evans, G. A., Margulies, D. H., Camerini-Otero, R. D., Ozato, K. \& Seidman, J. G. 1982 Proc. natn. Acad. Sci. U.S.A. 79, 1994-1998.

Garoff, H., Kondor-Koch, C. \& Riedel, H. 1982 In Current topics in microbiology and immunology, vol. 99 (ed. M. Cooper et al.), pp. 1-50. Berlin and Heidelberg: Springer-Verlag.

Garoff, H., Simons, K., Dobberstein, B. 1978 J. molec. Biol. 124, 587-600.

, Coligan, J. E \& Kindt T. J. I98 I Proc. natn. Acad. Sci. U.S.A. 78, 554-558.

Goodenow, R. S., McMillan, M., Örn, A., Nicholsen, M., Davidson, N., Frelinger, J. A. \& Hood, L. 1982 Science, Wash. 215, 677-679.

Goodfellow, P. N., Jones, E. A., Van Heyningen, V., Salomon, E., Bobrow, M., Miggiano, V. \& Bodmer, W. F. 1975 Nature, Lond. 254, 267-269.

Henning, R., Milner, R. J., Reske, K., Cunningham, B. A. \& Edelman, G. M. 1976 Proc. natn. Acad. Sci. U.S.A. 73, 118-122.

12 
Jay, G., Ferrini, U., Robinson, E. A., Khoury, G. \&. Apella, E. x979 Proc. natn. Acad. Sci. U.S.A. 76, 6562-6566. Katz, F. N., Rothman, J. E., Knipe, D. M. \& Lodish, H. F. 1977 J. supranolec. Struct. 7, 353-370.

Klein, J. 1979 Science, Wash. 203, 516-521.

Koch, G. L. E. \& Smith, M.J. I978 Nature, Lond. 273, 274-278.

Krangel, M. S., Orr, H. T. \& Strominger, J. L. 1979 Cell 18, 979-991.

Krangel, M. S., Pious, D. \& Strominger, J. L. 1982 J. biol. Chem. 257, 5296-5305.

Kreil, G. ro81 A. Rev. Biochem. 50, 317-348.

Kruppa, J. 1979 Biochem. J. 181, 295-300.

Kvist, S., Bregegere, F., Rask, L., Cami, B., Garoff, H., Daniel, F., Wiman, K., Larhammar, D., Abastado, J. P., Gachelin, G., Peterson, P. A., Dobberstein, B. \& Kourilsky, P. I981 Proc. natn. Acad. Sci. U.S.A.78, 27722776.

Kvist, S., Roberts, L. \& Dobberstein, B. 1982 EMBO Jl. (Submitted.)

Lalanne, J. L., Bregegere, F., Delabre, C., Abastado, J. P., Gachelin, G. \& Kourilsky, P. 1982 Nucl. Acids Res. 10, $1039-1044$.

Lingappa, V. R., Cunningham, B. A., Jazwinski, S. M., Hopp, T. P., Blobel, G. \& Edelman, G. M. I979 Proc. natn. Acad. Sci. U.S.A. 76, 3651-3655.

Malissen, M., Malissen, B. \& Jordan, B. R. 1982 Proc. natn. Acad. Sci. U.S.A. 79, 893-897.

Meyer, D. J., Krause, E. \& Dobberstein, B. I 982 Nature, Lond. 297, 647-650.

Moore, K. W., Sher, B. T., Sun, Y. H., Eakle, K. A. \& Hood, L. r982 Science, Wash. 215, 679-682.

Morré, D. J., Schirrmacher, V., Robinson, P., Hess, K. \& Franke, W. W. I979 Expl Cell Res. 119, $265-275$.

Nathenson, S. G. \& Cullen, S. E. I974 Biochim. biophys. Acta 344, 1-25.

Nathenson, S. G., Uehara, H., Ewenstein, B. M., Kindt, T.J. \& Coligan, J. E. I981 A. Rev. Biochem. 50, 1025-1051.

Örn, A., Goodenow, R. S., Hood, L., Brayton, P. R., Woodward, J. G.. Harmon, R. C. \& Frelinger, J. A. r982 Nature, Lond. 297, 415-417.

Orr, H. T., Lopez de Castro, J. A., Parham, P., Ploegh, H. L. \& Strominger, J. L. I979 Proc. natn. Acad. Sci. U.S.A. 76, 4395-4399.

Owen, M. J., Kissonerghis, A. M. \& Lodish, H. L. 1980 J. biol. Chem. 255, 9678-9684.

Parham, P., Alpert, B. N., Orr, H. T. \& Strominger, J. L. r977 J. biol. Chem. 252, 7555-7567.

Pearse, B. M. F. \& Bretscher, M. S. 198I A. Rev. Biochem. 50, 85-101.

Peterson, P. A., Rask, L. \& Lindblom, J. B. 1974 Proc. natn. Acad. Sci. U.S.A. 71, 35-39.

Ploegh, H. L., Cannon, L. E. \& Strominger, J. L. r 979 Proc. natn. Acad. Sci. U.S.A. 76, 2273-2277.

Ploegh, H. L., Orr, H. T. \& Strominger, J. L. I 98 г a Cell 24, 287-299.

Ploegh, H. L., Orr, H. T. \& Strominger, J. L. I98 I b J. Immunol. 126, 270-275.

Pober, J. S., Guild, B. S. \& Strominger, J. L. r 978 Proc. natn. Acad. Sci. U.S.A. 75, 6002-6006.

Pober, J. S., Guild, B. C., Strominger, J. L. \& Veatch, W. R. I98 I Biochemistry, Wash. 20, 5625-5633.

Pober, J. S. \& Strominger, J. L. I981 Nature, Lond. 289, 819-821.

Rask, L., Lindblom, J. B. \& Peterson, P. A. 1974 Nature, Lond. 249, 833-834.

Robb, R. J., Terhorst, C. \& Strominger, J. L. I978 J. biol. Chem. 253, 5319-5324.

Rothbard, J. B., Hopp, T. P., Edelman, G. M. \& Cunningham, B. A. ı980 Proc. natn. Acad. Sci. U.S.A. 77, $4239-4243$.

Rothman, J. E. \& Lodish, H. F. 1977 Nature, Lond. 269, 775-780.

Sege, K., Rask, L. \& Peterson, P. A. I98I Biochemistry, Wash. 20, 4523-4530.

Sood, A. K., Pereira, D. \& Weissman, S. M. I981 Proc. natn. Acad. Sci. U.S.A. 78, 616-620.

Steinmetz, M., Frelinger, J. G., Fisher, D., Hunkpiller, T., Pereira, D., Weissman, S. M., Uehara, H., Nathenson, S. \& Hood, L. I 98 I Cell 24, 125-134.

Steinmetz, M., Winoto, A., Minard, K. \& Hood, L. I982 Cell 28, 489-498.

Suggs, S. V., Wallace, R. B., Hirose, T., Kawashima, E. H. \& Itakura, K. I981 Proc. natn. Acad. Sci. U.S.A. 78, $6613-6617$.

Tabas, I. \& Kornfeld, S. 1978 J. biol. Chem. 253, 779-786.

Tabas, I., Schlessinger, S. \& Kornfeld, S. 1978 J. biol. Chem. 253, 716-722.

Tarentino, A. L. \& Maley, F. 1974 J. biol. Chem. 249, 811-817.

Tartakoff, A., Hoessli, D. \& Vassalli, P. I981 J. molec. Biol. 150, 525-535.

Terhorst, G., Robb, R., Jones, C. \& Strominger, J. L. I977 Proc. natn. Acad. Sci. U.S.A. 74, 4002-4006.

Trägårdh, L., Rask, L., Wiman, K., Fohlman, J. \& Peterson, P. A. I980 Proc. natn. Acad. Sci. U.S.A. 77, 11291133.

Vitetta, E. S. \& Uhr, J. W. I975 J. Immunol. 115, 374-381.

Walsh, F. S. \& Crumpton, M.J. 1977 Nature, Lond. 269, 307-311.

Walter, P. \& Blobel, G. r981 J. Cell Biol. 91, 557-561.
Warren, G. 1980 In Comprehensive biochemistry (ed. R. Michel \& B. Finean), vol. 1, pp. 215-257. Amsterdam: Elsevier/North-Holland.

Zinkernagel, R. M. \& Doherty, P. C. r974 Nature, Lond. 148, 701-702. 